\title{
O lado de lá das artes
}

Fábio D'Almeida ${ }^{I}$

A REPUBLICAÇÃo do livro Belas artes: estudos e apreciações (1885), de Félix Ferreira (1841-1898), vem jogar nova luz aos estudos sobre a arte brasileira do século XIX, atualizando um panorama de avaliação crítica para o qual as produções desse período têm sido conduzidas desde os anos 1980. Empreendida pelo professor Tadeu Chiarelli e editada pela Zouk, a publicação segue algumas orientações de pesquisa e formação desse estudioso que, a partir de 1995, inaugurou, com o hoje bem conhecido $A$ arte brasileira (1888), de Gonzaga Duque (18631911), a sua participação na reedição de fontes originais sobre a arte nacional, a fim de serem mais facilmente acessadas pelo público geral e especializado.

Conquanto um holofote centrado em uma mesma área, a luz que o livro de Ferreira empresta aos estudos sobre arte brasileira do oitocentos é, no entanto, uma de outra sorte cromática, que faz notar alguns elementos que pouco interessaram a outros críticos brasileiros do mesmo período, incluindo-se aí o seu colega de pena no Arte brasileira.

Enquanto Gonzaga Duque tornar-se-ia, no Rio de Janeiro, expoente da crítica de arte produzida entre as últimas duas décadas do século XIX e início do XX (sobretudo pintura e escultura), Ferreira esteve longe de se converter em um crítico especializado da área. Isso ele próprio o reconheceu, não apenas no Belas artes, mas em outros textos que imprimiu em sua longa carreira como jornalista. Ferreira era, de outro modo, na avaliação certeira de Chiarelli, um "publicista” (p.11); e a essa qualificação se poderia ainda somar outra: a de militante.

Desde a década de 1860, quando ligado à Biblioteca Nacional, seus planos se atualizam na participação contínua de projetos culturais e educacionais para a sociedade brasileira, cujos principais prismas irradiadores, segundo defendia, seriam a palavra impressa e a imagem gravada, ativadas em folhetos, jornais e, principalmente, em livros.

Não poucas vezes contestou a falta de "livros instrutivos e ilustrados" no país, "postos ao alcance dos menos favorecidos de fortuna" (Ferreira, 1881, p.7). Sua aspiração não era a de produzi-los como perpétuos, mas como objetos portáteis correntes, difusores importantes de ideias para o "progresso" de um povo - mormente o de um ainda preso às amarras escravistas, mesmo que testemunhasse leis graduais para o seu afrouxamento. Em fomento a essa empreitada, escreveu sobre quase todo tipo possível de assunto: saúde, economia, política, ciências, educação, turismo, história, artes.

Belas artes: estudos e apreciações é o primeiro fruto desse último ramo, no qual o autor anunciava já concluir outra publicação de mesma natureza, mas que parece não ter sido concretizada. Coletânea de textos originalmente entregues esparsamente à imprensa ao longo de vários anos, esses escritos foram formatados em livro num importante período de expansão do mercado livreiro no Brasil, para o qual Ferreira, sintomaticamente, deu incessante contribuição não apenas como escritor, mas também como edi- 
tor de autores novos e clássicos e mesmo como dono de uma empresa tipográfica. ${ }^{1}$ Conhecia, portanto, todos os percursos e percalços da prática editorial, tal como os profissionais mais ilustres do período, Louis Garnier e os irmãos Laemmert, vizinhos do brasileiro nos arredores da efervescente Rua do Ouvidor, além de eventuais parceiros comerciais e colegas de soirées literárias.

O esforço de Ferreira, ao menos no campo editorial das artes, foi exemplar, conforme também notado por Chiarelli. Belas artes parece ter sido "o primeiro livro dedicado à história da arte publicado no Brasil" (p.9) por um autor nativo. Participante do mercado editorial, Ferreira o sabe e estrutura seu impresso em duas partes que, se desviadas do importante dado de sua primazia, poderiam fazê-las parecer a princípio incoesas.

$\mathrm{Na}$ primeira parte, Ferreira apresenta um "Estudo histórico", bloco no qual empreende uma leitura da história da arte universal, essa por sua vez seguida pelo que compreendia serem os estágios irrefutáveis da arte - e mesmo de toda atividade humana. Origem, gênese, infância, formação, desenvolvimento, progresso, transformação, florescimento, grandeza, apogeu, maturidade, decadência, renascimento são conceitos recorrentes nessa primeira parte do livro, e retomados com mesmo fôlego durante a segunda parte. Eles sugerem a aproximação de Ferreira com uma abordagem de muitas "histórias culturais" do oitocentos, que supunham ser possível perceber e reconstruir, pela análise dos diversos produtos do homem, as características sociais distintivas do povo e do período em que teriam sido formatados.

Expondo vários de seus interlocutores - a grande maioria franceses, cujos li- vros eram publicados havia pouquíssimo tempo -, Ferreira não esconde que não deseja divulgar toda a arte universal então conhecida, mas construir uma filiação interessada em algumas produções consagradas na história, essas que seriam "naturalmente" mais afeitas aos brasileiros, em razão de sua "latinidade" e do seu evidente lastro europeu. Se Belas artes é publicado num mesmo período em que se discutem, à luz da incipiente arqueologia nacional, as "produções artísticas" e o legado da cultura indígena no Brasil, não deve restar dúvidas de que Ferreira, tendo também participado desse debate, ${ }^{2}$ conclui que não é para com os gentios, com sua civilização "infantil" e arte "imperfeita", que o brasileiro mantinha dívidas. A última expressão verdadeira da sua herança artística seria o ainda vigente (e bem quisto) predomínio internacional da arte francesa; e a primeira, a da Grécia clássica.

Com vistas nessas duas balizas - a de uma Antiguidade perene com que inicia o livro, e a de uma Modernidade francesa inspiradora, com a qual termina a primeira parte -, Ferreira prepara a segunda parte do seu livro, pois advoga perceber o Brasil no desdobrar de um mesmo percurso histórico de grandes nações, submetido, do mesmo modo, às variações contínuas dos seus estágios cívicos e artísticos. ${ }^{3}$

"Nação nova", mas não mais infantil, a sociedade brasileira e, por conseguinte, as suas artes estariam na fase de "formação", na qual as promessas do presente, se ancoradas nas experiências do legado europeu, eram ansiadas como certezas de um futuro próximo: vislumbre positivo de um autor quadragenário, que contrastaria bastante com o pessimismo expresso três anos depois pelo ainda 
vintaneiro Gonzaga Duque. 4 De todo modo, a periodização de Ferreira antecipava, curiosamente, a mesma estratégia que seria adotada por Duque no $A$ arte brasileira, quando também conduzia seu livro - contudo com maior rigor esquemático - entre estágios progressistas da arte nacional. ${ }^{5}$ A afinidade pode não ser casual, posto que os dois escreveram para os mesmos periódicos, e é improvável que não tenham travado algum contato, ou que, ao menos, não tenham se aproximado de um mesmo arcabouço teórico derivado de uma bibliografia estrangeira comum, tão acessada por intelectuais de áreas afins.

Maiores semelhanças entre os livros desses dois autores acabam, todavia, aí. No exato ponto onde os seus estudos acordam se situa, justamente, a outra sorte cromática que Ferreira empresta a seu texto, em especial à segunda parte, dedicada unicamente à arte brasileira. Se Duque, e mesmo outros críticos brasileiros, mantém foco regular no primeiro escalão das artes e dos artistas do século XIX, o engajamento com a instrução pública assumido por Ferreira, e a crença na força que os artistas teriam nesse âmbito e no da indústria, deve ter influído para que o tom e os objetos de suas apreciações se concentrassem no que se pode compreender por um "lado B" das artes no Brasil.

Pintura e escultura merecem espaço em seus estudos, mas não menos quanto o merecem outras artes e "gêneros" menores. Parcela significativa do texto é dedicada à arquitetura brasileira do oitocentos, alternada pari passu por apreciações sobre xilogravura, litografia, fotografia, tipografia, guache, pastel, desenho, moldagem em ferro e trabalhos em seda - algumas práticas que, ainda hoje, poderiam ser questionadas se merecedoras de figurar em um livro sobre "belas artes". Ferreira abre ainda terreno para um "gênero" dito amador, pouco explorado no Brasil do século XIX, incluindo críticas a trabalhos de mulheres. ${ }^{6}$

À exceção de algumas cartas marcadas incontornáveis (como Victor Meirelles e Pedro Américo), a grande maioria dos artistas abordados pelo autor também permanece sem maior representação nos estudos da história da arte brasileira e, talvez por isso, seja possível que também não se percebam a coerência e o interesse por ele empregados quando os torna chaves de sua atenção. São quase todos artistas que integram um circuito profissional e expositivo paralelo ao da Academia Imperial de Belas Artes (instituição central das artes no século XIX) e, mais do que isso, muitos deles ligados (enquanto professores ou alunos) ao Liceu de Artes e Ofícios do Rio de Janeiro: escola fundada pelo arquiteto Bethencourt da Silva, ${ }^{7}$ voltada sobretudo para o ensino artístico de artesãos e gráficos, e não especificamente para o de artistas plásticos.

O interesse de Ferreira nesses “operários" (tanto, ao ponto de afirmar: "artistas industriais como esses é que são os verdadeiros operários do progresso” (p.185)) parece reiterar a sua atuação naquele projeto de desenvolvimento social e material do Brasil, chamando a atenção para a importância desses profissionais nesse sentido. O livro de Ferreira mesmo, enquanto exemplar de um instrumento básico, obrigatório à educação, necessitaria dos serviços de tipógrafos e ilustradores bem instruídos. $^{8}$

Em suas escolhas, o autor demonstra dificilmente perceber as artes em um domínio isolado. E nem as queria assim, 


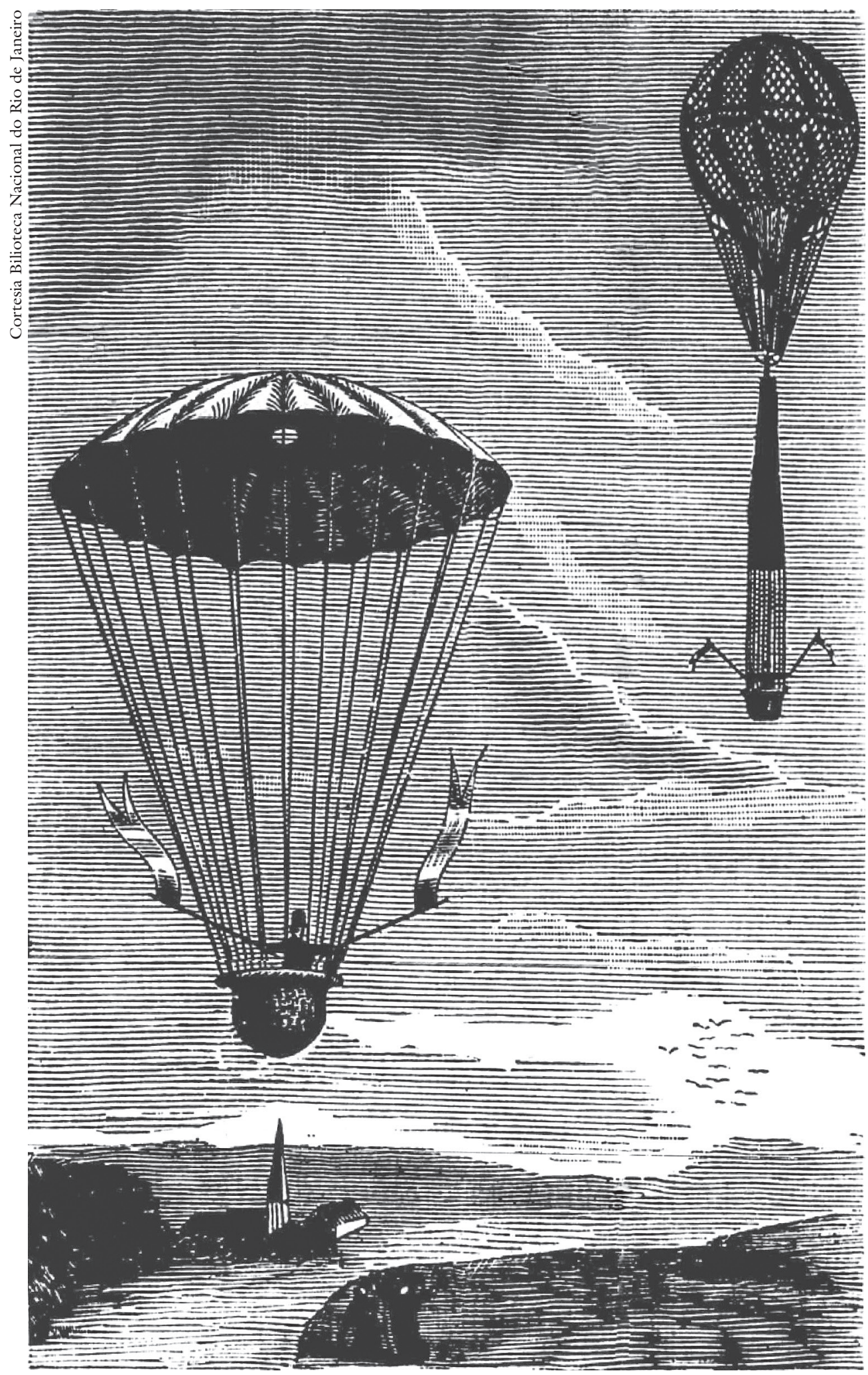

Imagem que acompanha matéria sobre a invenção e uso do Aerostato, publicada na primeira edição do periódico Sciência para o Povo, criado por Félix Ferreira, em 1881. 


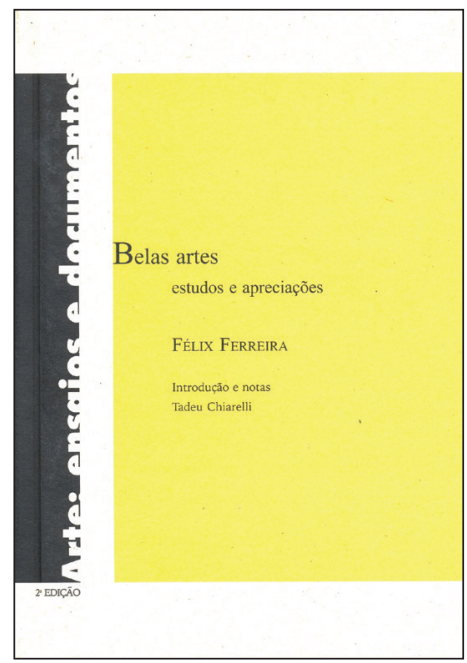

FERREIRA, F. Belas artes: estudos e apreciações. São Paulo: Zouk, 2012.

pois se eram a expressão do "progresso" de um povo, quanto mais cedo fossem por ele abraçadas, tão logo ao corrente estágio de "formação" da nação brasileira sucederia o do "desenvolvimento"; e a esse, o do "brilhantismo".

É nessa postura assumida que parece estar a imediata contribuição do Belas artes para a história da arte brasileira, porquanto nele o autor esboça uma visão dessa história como uma disciplina que se constrói de relações sociais e práticas artísticas amalgamadas, na qual cada uma, "maior" ou "menor", possui importância indelével para um fim moralmente elevado.

Recebido hoje, o livro talvez torne-se desde já mais importante pelas perguntas que abre para um campo ainda pouco explorado das artes brasileiras, do que por qualquer resposta oferecida por mãos fáceis: perguntas sobre um "lado B" que, até que se atravesse a brecha do muro aberta por Félix Ferreira, permanecerá sendo o lado de lá das artes no século XIX.

\section{Referências}

FERREIRA, F. (Ed.) Sciência para o povo: Serões Instrutivos. Ano I, vol.l. Rio de Janeiro: Lombaerts \& C., 1881.

HALLEWELL, L. O livro no Brasil. São Paulo: Edusp, 2005.

\section{Notas}

l É bastante possível que a Tipografia Imparcial de Ferreira tenha sido comprada da viúva ou de parentes de Paula Brito (um dos primeiros e maiores editores-impressores de livros do Brasil durante primeira metade do século XIX), que possuiu, anos antes, tipografia com o mesmo nome (cf. Hallewell, 2005).

2 Para a I Exposição Antropológica Brasileira, em 1882, Ferreira escreveu, a convite de Ladislau Netto, diretor do Museu Nacional, um texto sobre as artes dos indígenas, publicado na revista da mostra, em 1883.

$3 \mathrm{O}$ seguinte trecho do Belas artes é, nesse sentido, especialmente revelador: "Cumpre não esquecer que as artes em todos os tempos e países têm tido sucessivamente períodos de infância, desenvolvimento e brilhantismo, e não poucas vezes até de decadência e renascimento. Não estamos, é certo, no primeiro período, o da infância, mas também ainda não chegamos ao do desenvolvimento: achamo-nos, sim, no da formação, que coincide com o período da ebulição social que atravessamos.." (p.181).

4 Foi esse pessimismo, alternado por momentos mais brandos, o dado que levou Tadeu Chiarelli a perceber uma "moldura" e um "quadro" nas críticas do $A$ arte brasileira, quando concluía a introdução para a nova edição do livro de Duque, em 1995. 
5 São eles: "causas”, "manifestação”, “movimento" e "progresso".

6 As produções femininas são um interesse caro a Ferreira, que defendeu e festejou, mesmo em outros livros, a instalação do ensino artístico para o sexo feminino no Liceu de Artes e Ofícios - RJ, em 1881.

7 Bethencourt é uma figura por quem Fer-reira, por amizade e proximidade de interesses, nutre grande admiração, ao ponto de dedicar, ainda no Belas Artes, um perfil artístico.

8 Em trágica ironia, Ferreira foi, no Belas artes, vítima de sua própria causa. A defesa que fez em favor do ensino artístico encontrou como limitação o próprio fato de não poder imprimir em seu livro as imagens que desejava, reclamando nele, em nota, a carência de profissionais e estruturas mais acessíveis no Brasil. Redenção belamente feita por Chiarelli e pela Zouk, na nova edição, que dispõe das desejadas ilustrações.

9 A distinção parece válida porque Ferreira, apesar de várias concessões, não consegue abandonar uma tradicional escala de valores ainda vigente entre as diferentes artes manuais, na qual pintura e escultura ainda permaneciam como exemplos máximos.

Fábio D'Almeida é doutorando em História, Crítica e Teoria da Arte no Departamento de Artes Plásticas da ECA-USP. Membro do Grupo de Estudos Arte \& Fotografia do mesmo Departamento. Editor e colaborador da Enciclopédia de Artes Visuais do Itaú Cultural.

@ - fabioufes@gmail.com

I Escola de Comunicação e Artes, Universidade de São Paulo, São Paulo/SP, Brazil. 